\title{
The Role of Private Higher Education Provision in Zambia: Changing the Higher Education Landscape in Africa
}

\author{
Daniel L. Mpolomoka, Z \\ Ambian Open University \\ AMBIA \\ Selina Band \\ Mbono Vision Dube \\ Zambian Open University \\ Akombelwa Muyangana \\ University of Zambia \\ Esther Kanduza, Zambian \\ Maina Kaleba, Zambian \\ Open University
}

\begin{abstract}
This paper is anchored on the assumption that the world is approaching the end of two important international initiatives, the Decade of Education for Sustainable Development (2014) and the Millennium Development Goals (2015). Given such a scenario, Africa is gaining increased attention due to the innumerable challenges it faces in striving to achieve sustainable development. There is unanimity that African countries should improve their capacities to cope with emerging challenges. As a result, their higher education institutions need to drastically improve their own educational programmes and associated research facilities for training future generations of skilled personnel. This paper concludes by making critical observations on the general populace's expectations of private higher education learning institutions.
\end{abstract}

Keywords: Private higher education, Africa, Zambia, Learning

\section{Introduction}

The world we live in is radically changing from that of a couple of decades ago. It is an era of globalization, with growth of economic and social activities across national boundaries being common features. Berdahl (2008) outlines some of the major changes today, which include technological revolution in communications (the internet and large-scale computerized information systems). Given such circumstances, both public and private institutions of higher learning face many challenges of local, national and global context. It is often said that in order to compete globally, participation in Higher Education acts as a perfect bridge, developing a range of skills, knowledge, values and competencies which are essential to survive in highly-competitive environments. Without doubt, such breeds a mechanism which enhances the quality of life, enlightens individuals' vision and gives a broader perspective of life. In this paper, higher education will refer to education beyond the secondary education level, especially education at the college and, or university level. The paper discusses two issues:

- The first is about private higher learning institution's involvement in the provision of science ${ }^{1}$ and technology-biased subject areas in Zambia.

- The second one is the impact of private higher education provision in Zambia.

\footnotetext{
${ }^{1}$ Refers to all subject areas with science as a major component, e.g. nursing, medical doctor, clinical officer course, dentistry, ophthalmologist, speech therapy, physiotherapy, agriculture, pharmacy, engineering,etc.
} 


\section{The Brief Backdrop}

When Zambia got her independence, higher education provision was limited and State driven. During that time, two distinct higher education areas existed, one specifically addressing teacher education and the other technical and further education. Then, the private sector was neither mandated to own nor run any higher education institution. The State owned all the science and technology-oriented higher education institutions which existed between the period 1964 and late 1990s. The question we can pose is what was the impact of such monopoly?

The impact of the monopoly is unquestionably grave. Since Zambia's population was booming, there was need to expand existing higher education institutions. What is more, government funding to higher education institutions was ever meager to meet the ever escalating needs of institutions. MoE (1996:93) further notes that: The demand for admission to higher institutions is very high and is far from being satisfied. More than 20, 000 pupils complete secondary school each year. Of these, 13, 000 or more obtain a full certificate. Meanwhile, the higher institutions have a total annual intake of about 5,000. Only a quarter of the applicants to higher institutions are admitted each year. But the major reason is that admission capacity in higher education institution falls short of the demand.

Distance learning ${ }^{2}$ in Zambia had for a long time being neglected and not accepted as a form of learning that is credible and was viewed to be sub-standard. Today, distance education once a poor and often unwelcome stepchild within the academic community, is becoming increasingly more visible as a part of higher education (Merisotis and Phipps, 1999). But the question we ask again is how many distance learning, private owned higher education institutions offer science and, or technology biased subject areas?

Between 1964 and the late 1990s, private partnership in education provision was not there. Thereafter, Even though a cross section of public higher education institutions evolved to meet changing times, there exist gaps in what they provide. We will begin by outlining specializations of private higher education institutions and then establish the missing link (the gap).

\section{Changes in higher education landscape in Zambia}

Changes in the higher education landscape in Zambia have been necessitated by modernization on one part and local and international competing factors on the other.

As early as the times of the first Republican president in Zambia (Dr. Kenneth Kaunda), advocacy for expansion of higher education had begun. Setting the pace for expansion of educational facilities in Zambia, Dr. Kenneth Kaunda ${ }^{3}$ said:"Expanding our Secondary School Education and paying greater attention to the requirements of university education, in order to produce qualified personnel... and help establish sound administrative cadres for upper and middle grades in government, commerce and industry, agriculture extension schemes and public works, for which good education is a must - has no substitute."

Since there was need to build indigenous human resource (Zambian skilled manpower), many were trained both locally and abroad in critical skill areas, which included: electrical installation, motor vehicle mechanics, brickwork, carpentry, to mention but a few. It must be mentioned here that many either obtained first class or second class passes, or craft certificates (Northern Rhodesia, 1963:2). Though the trend has continued today, it ought to have grown and been expanded massively.

The question we are posing is: it is now five decades after Zambia got her independence, has she managed to house a higher education institution (public ${ }^{4}$ or private) offering certification beyond Diploma in brickwork, bricklaying, carpentry?

The then Ministry of Science Technology and Vocational Training 5 provided technical education, vocational and entrepreneurship training through its training institutions and colleges spread throughout the country. At least, the Ministry has twenty three training institutions (see appendix one for details) offering courses at trade, craft/certificate, technician/advanced certificate and technologist/diploma levels.

\footnotetext{
${ }^{2}$ Also known as Open and Distance Learning (ODL)

${ }^{3}$ Former Zambian Republican President: Foreword to 'Growth of Education in Zambiasince Independence' by J.M.

Mwanakatwe. Revised Edition.

${ }^{4}$ Even though our concern is solely private higher education, to make a comparison, checks and balances of the higher education system, reference to public higher education will be made time and again.

${ }^{5}$ Now part of the Ministry of Education, Science, Vocational Training and Early Education (MESVTEE) 98
} 
The private sector also rallies behind the government in providing technical education in Zambia. Prominent among them include those initiated by non-governmental organisations (NGOs), faith-based organisations (FBO), Individuals and Individual Groups of people. One of them is 'Zdithandizeni' ${ }^{6}$ in Garden Compound, which offers carpentry and joinery to orphan and vulnerable people and the general public.

We suppose, the country should have improved this type of higher education and initiated Diploma and Degree certifications, especially that the Government of the Republic of Zambia now allows the private sector to own and run higher education institutions. Suffice though to say, Maliyamkono and Mason (2006:16) observe that maximizing the realization of these possibilities is still problematic as evidenced for example that to date in Africa there are still a great number of people who are missing out on higher education. The importance such a transition can have on an economy is needless to overemphasize. For instance, MoE (1996) acknowledges that: A critical function of higher institutions is the provision of education to students. This teaching function requires that besides imparting bodies of knowledge in the various branches of learning,...institutions develop the creative, communicative and problem-solving skills and capabilities of their students....their ultimate purpose is the improvement of human lives through enlarging human capabilities and enabling those capabilities to be put to the best use in all fields - economic, social, cultural, scientific and political. Despite these shortfalls highlighted, in the five decades after Zambia became independent, higher education in Zambia has evolved from covering two higher education areas (teacher education and; technical and further education) to include other education systems.

\section{The role of private higher education institutions}

The key question we sought to probe here was: what is the role of private higher education institutions?

The role of higher education (private and public) cannot be framed in separation from the context and conditions in which it must play its role. Thus, the role of higher education must interconnect and involve economic and social challenges of local, national, intercontinental and global contexts. Saleem Badat (2009:7) consents that these challenges include the imperatives of economic growth and development; the ability to compete globally; job creation and the reduction/elimination of unemployment and poverty; the effective delivery of social services and the threat of HIV/AIDS and other diseases. But do private higher education institutions in Zambia manage to do this?

The challenges being uncovered here also comprise the imperatives of equity and redress social justice; the democratization of state and society; the building of a culture of human rights, creating a vibrant civil society, and promoting a culture of vigorous and critical intellectual public discourse. In playing its role, higher education should also be guided by and stand for specific principles and values. These include: equity and redress, quality, development, democratization, academic freedom, institutional autonomy, effectiveness and efficiency, and public accountability. Are the rapidly expanding private higher education institutions meeting these differentiated needs of the society? Enriching the Zambian market economy? The subsequent paragraphs will try and answer these seemingly difficult question areas. Questions like these are not easy to answer especially that documentation of activities and dissemination of research findings rarely takes place in Zambia.

According to O'Neill, Singh, O'Donoghue (2004:48) the increased demand to higher education can be attributed to the knowledge driven society. It is common knowledge to day that society needs higher levels of skills and qualifications to fill the same worthwhile jobs. Higher education can help economies to catch up with more technologically advanced societies. Graduates are likely to be more aware of and better able to use new technologies.

The aforementioned is similar to what Davies (O'Neill, Singh and O'Donoghue, 2004) alludes to by observing that education has become a commodity in which people seek to invest for their own personal gain, to ensure quality of opportunity and as a route to a better life. They further contend that the demand for higher education is expanding exponentially throughout the world and by 2025 as many as 150 million people will be seeking higher education. In the event that education has become a commodity, private owned higher education institutions should take advantage, even though at present the programmes they offer are all tilted towards education, business with very few if none offering science and technology biased subject areas.

\footnotetext{
${ }^{6}$ A Nyanja term; in English it means, 'Help Me'.
} 
There a number of roles that higher education must play, whether private or public. We have discussed six in this paper, which we feel are critical.

\section{Democracy and democratic citizenship}

The first crucial role of higher education is to contribute to building a critical and democratic citizenship.

Societies require graduates to be capable professionals, sensitive intellectuals and critical citizens. This is a mandate private higher education must champion. This collaborates with what Saleem Badat (2009:7) notes regarding higher institutions of learning that "our academic programmes together with our institutional culture and practices must therefore ensure that we keep ethical questions in sharp focus, and that we advance a democratic ethos and a culture of human rights conducive to critical discourse, cultural tolerance, and a common commitment to a humane, just, non-racist and non-sexist social order." O' Connel (2006) also echoes the same point regarding institutions of higher learning that they are "tasked with the arduous formation of a critical, creative and compassionate citizenry. Nothing less will suffice". In a speech by former United Nations (UN) secretary general Kofi Annan, he argues that:

The University must become a tool for Africa's development in the new century. Universities can help African expertise; they can enhance the analysis of African problems, strengthen domestic institutions, serve as a model environment for the practice of good governance, conflict resolution and respect for human rights, and enable African academies to play an actual part in the global community of scholars.

In Zambia, like elsewhere, the trend has been to approach higher education and investment in institutions of higher learning from the perspective largely of the promotion of economic growth and the preparation of students as productive workers for the labour market and economy.

Clearly, we are not disputing that higher education must cultivate the knowledge, competencies and skills that enable graduates to contribute to economic development, since such development can facilitate initiatives geared towards greater social equality and social development. But we are keenly looking at the role private higher education institutions play in providing education and the impact they make.

What comes out quite clearly from the document analysis is that there is need for urgent restructuring of programmes to make curricula match more with the knowledge, expertise and skills needs of a rapidly changing economy.

It is important to avoid conceiving higher education in purely political and instrumental terms for this may miss its potential cultural, expressive and symbolic contributions. Regarding this Melucci (1989) observes that while higher education may have visible effects such as helping bring about institutional changes and cultural innovation relating to new forms of behaviour and social relationships. Suffice to say that much of its activities may take place on a symbolic plane.

\section{Cultivation of highly educated people}

This is yet another role of higher education. It is aimed at cultivating highly educated people. To reach this milestone, institutions of higher learning in Zambia ought to provide ingeniously, carefully conceptualised and applied teaching and learning programmes that take into account several issues, among them two key ones.

The first one relates to the kinds of knowledge, competencies, skills and attitudes that graduates require to function in a rapidly changing society, nation and global world. Programmes these institutions offer must be aimed at enabling students graduate as professionals who can think theoretically and abstractly; collect and analyse information with precision; make constructive criticism and be able to communicate effectively in both speaking and in writing.

The second aspect involves the social and educational experiences of learners. Often learners engaged in higher institutions of learning come from increasingly diverse social backgrounds. This is the more why there should be equity of opportunity and effective teaching-learning to foster academic development and mentoring programmes. Prof. Dickson Mwansa, the Pro-Vice Chancellor of the Zambian Open University (ZAOU), is pertinent here when he states the fundamental reasons for the existence of institutions of higher learning. According to him, institutions of higher learning must meet the needs of learners, not be static, raise to the occasion and above all, help the government by offering subject areas that are lacking among many in society. 
Institutions of higher learning play an instrumental role in helping develop individuals, society and the nation. This collaborates with what Prof. Brian O' Connel (2006), Vice Chancellor of the University of Western Cape, observed that universities cannot rest on their laurels... and simply teach the same curricula...year after year with minor changes and presume that this is sufficient. If the demands made on students by a fast-changing world are greater, so too are the demands on lecturers and researchers. Then our role has to be re-shaped so that we constantly unpack the assumed constants in our respective fields in order to encourage students to interrogate what we and they have learned to take for granted.

\section{Research and scholarship}

Research and scholarship is another role of higher education. A critical analysis reveals that currently the Zambian Open University with a very negligible number of private colleges are actively engaged in research. But it is vital to understand here that research is cardinal and crucial for every higher educationinstitution. Boyer (1990) also acknowledges that institutions of higher education must carry out different kinds of research. In a fastchanging economy like Zambia, knowledge creation and transmission is central development. This is the reason why Carnoy (1998:2) contends that a key feature of the global economy is that the accumulation of capital is 'increasingly dependent on knowledge and information applied to production, and this knowledge is increasingly science based'.

Building on Carnoy's point of view, Castells (1993) contends that "if knowledge is the electricity of the new informational international economy, then institutions of higher education are the power sources on which a new development process must rely". This definitely underscores the great importance of research higher education institutions undertake.

\section{Development needs and challenges}

Institutions of higher learning should be actively engaged with various pressing developmental needs and challenges of individuals, societies and the nation at large. Through teaching and learning, institutions of higher learning develop nations' different sectors (economy, education, health, environment, etc.). This enables them use research to contribute to the management and resolution of issues and problems affecting societies. According to Stanton (2008:2-3) alongside, community engagement and service-learning can serve as a "means for connecting universities and communities with development needs" and "for higher education staff and students to partner with communities to address development aims and goals". Institutions of higher education should create partnerships with communities that have potential to offer opportunities for economic and social advancement, while at the same time enriching and enhancing research and learning and teaching.

\section{Intellectual and cultural development of societies}

This role of higher education calls for proactivity and active engagement with societies. This is done with a sole aim of contributing to the intellectual and cultural development of a critical citizenry. Institutions of higher learning, according to Gould (2006), have an immense responsibility of "conveying the power and beauty of science to the hearts and minds of a fascinated, if generally uninformed, public". This collaborates with what Gould (2006) notes that there is a 'long and honourable tradition of popular presentation of science', and we should not make the 'mistake' of 'equating popularization with trivialization, cheapening, or inaccuracy'. He rightly states that 'the concepts of science, in all their richness and ambiguity, can be presented without any compromise, without any simplification counting as distortion, in language accessible to all...people'. Leuny Morel points out that "countries that will invest in talented graduates in innovation, science, engineering, technology will undoubtedly advance economic and social progress in comparison to their counterparts that will be unwilling to grow their human talented pool". This raises questions worth pondering over.

- Do our private institutions of higher learning communicate beyond their confines?

- Do their scientific communities indicate that they engage sufficiently with the public and serve adequately as catalysts of critical public education and intellectual debate?

- Do they advance the higher education's rationale of advancing the public good?

These questions are meant to uncover other unthought-of target areas of private and public institutions of higher learning. Higher education in this regard should not merely be content with simply transmission of 'body of knowledge' to users in society, but actively involve them inreflexive communication. 
This is what Delanty (2001:154) refers to as an 'argumentative, critical and thoughtful engagement that shapes the very constitution of knowledge'. Without doubt, institutions of higher learning need to give attention to innovative strategies and mechanisms to promote and facilitate such engagement.

\section{Impact of Higher Education}

The core question area which guided us was Have the roles of private higher education institutions made any impact on individual learners, society and the nation at large? This is addressed in the subsequent two subheadings.

\section{Science related subject areas}

Science related subject areas have posed a great challenge to many institutions of higher learning. The problems range from teaching-learning materials and equipment to infrastructure. Both full time, and open and distance learning privately owned higher education institutions seem to be failing to match to the standard, on one hand; and unable to meet the insatiable desire by the general populace (potential students) to be engaged in those study areas (programs).

In almost all the provinces of Zambia, there is at least one private owned nursing school. This is unprecedented; especially that government also established nursing schools in almost every provincial capital. The private nursing institutions have helped cushion the market demand for nurses. An inventory of benefits to individual, society and nation, which has resulted, is unquestionable. As early as 2005, a private run nursing school was set up. It struggled to gain recognition and enroll. It faced a lot of political, attitudinal and financial challenges that it eventually collapsed. Albeit this, students who did not complete their course of study were transferred to a public nursing school. A clear manifestation of collaboration I have earlier hinted on, which can be sustained.

This corroborates with what Sikwebele notes: The contribution of higher education is different at various levels. At the tertiary level, some colleges are affiliated to universities. This ensures a close working relationship between them in terms of quality assurance in the syllabuses, examinations, instruction and other aspects of the college curricula. Specialist doctors, teachers, economists, agriculturists, and others are trained in higher education institutions. Further, higher education provides research capacity to individuals and institutions. Research done by staff in higher education is important in providing data for planning, policymaking and reform in education.

We must hasten to mention here that colleges (both private and public) affiliate to either public or private universities. The trend seems to be more pronounced in nursing institutions and education.

Time and again, private higher education institutions are not seen offering certain subject areas like forestry. Apart from Mwekera Forestry College, a public owned, no private higher education institution offers forestry. The institution offers craft certificate and Diploma certificates in forestry. Meanwhile, the Copperbelt University (a public institution) is the only institution in Zambia that offers bachelors degree and masters programmes in agro forestry and wood science. In growing economy like ours (Zambia) conservation of natural resources and management of forestry is paramount. The question we are posing today is how will Zambia manage to champion global warming, forestry and agroforestry management with such limited human resource? What is hindering private institutions from running subject areas in this regard?

In Zambia, there seem to be more concentration on research on the arts, humanities and social sciences to the detriment of the natural, medical and engineering fields of study. Regardless of the hiccups faced, research is important and must be promoted. This collaborates with the observation by Mkandawire (2009:vii) that "attempts to improve Africa's prospects by focusing on scientific advances and the benefits accruing from them have all too often overlooked the important perspectives which the humanities and social sciences afford" and "it is vital that the social sciences and humanities are granted their rightful place...if Africa's development challenges are to be fully and properly addressed".

\section{Technology related subject areas}

It is sad to note here that the majority of institutions offering technology biased courses are public and not private ones (see appendix one for details). It is very hard to trace the input of private higher education institutions in this regard. This is primarily because it is in piecemeal, segregated and unmonitored. No wonder the Zambia National Education Coalition (ZANEC) observed that the tertiary education in Zambia is a disaster(Mulenga, 2010). 
The then Science and Technology Minister Dr. Brain Chituwo said there was need for TEVETA to strengthen boards in all skills training institutions.....to improve the quality of education among the skills training institutions (Mulenga, 2010). No mention was made of the need to encourage the private to own higher education institutions to beef up public ones, but at least the Minister talked about ways of sensitizing the general public (potential learners) about the various technology-biased subject areas offered by TEVET.

\section{Relevance of programmers offered by private higher education institutions}

There is no doubt that programmes offered by private high education institutions (PHEI) are timely and crucial to individual, societal and national development. However, step-by-step critique of the programmes reveals pitfalls which are worth exploring and bridging. The majority of higher education institutions either offer education related course and, or business courses.

The relevance of science subject areas offered by private nursing schools is unquestionable. But they need to raise to the occasion and improve quality and standard. Even though, the media and Ministry of Health deregisters and closes some, the number is very small. In October 2013, one school of nursing in Livingstone was closed.

Furthermore, the document review undertook indicates that far less than quarter of private high education institutions offer science and technology biased subject areas. The Northern Technical College (NORTEC) in Ndola so far is unmatched. To date, there is no private higher institution in Zambia that offers courses NORTEC does. In as much as the private sector wants to support and supplement government effort in the provision of education, it should be strategic and venture into seemingly isolated, neglected study areas.

\section{The Great Peril}

In the event that public institutions of higher learning do not meet the demand of the general populace and private institutions do not come in to bridge the eminent gap in service provision, an unending gulf in higher education will continue to exist. This in turn will have a trickle-down effect. Individuals and communities will be deprived of essential skilled personnel with science and technology oriented skills. The recent past has witnessed many privately owned higher institutions of learning proliferate offering science and technology based subject areas. Their attempt to operate at below per status (without equipment, machinery and specialized laboratory facilities) has in recent days been reported in the mass media. The 'white-collar job syndrome' seems to have gripped many of us that we cannot imagine sending our children to pursue trades-oriented subject areas. In as much as, we are advocating for collaboration, involvement of private higher education institutions in providing science and technology biased subject areas, potential learners might not be there (not forth-coming). This is the greatest challenge all the trade schools (listed on appendix one) face. Who will send their child to pursue a university degree in bricklaying, plumbing, carpentry? is the question that all of us can answer.

\section{The Way Forward}

Already existing institutions of higher learning should consider partnering (affiliating) with public institutions to offer seemingly scare, difficulty subject areas (science and technology). The Government of the Republic of Zambia, like many other governments world over, should initiate scholarships specifically in science and technology related fields to individuals already practicing and other potential individuals. For example, the mass media in Namibia carry scholarship articles for Namibian citizens to apply for scholarships in identified eschewed areas like technology, science to mention but a few. We would like to salute the MESVTEE for providing guidance to both public and private universities and colleges regarding teacher training requirements. By out rightly setting a profile of teacher, standardization and quality of training is assured. Sensitizing needs to be carried out. As it stands, many have not accessed the new curriculum and find it difficult to conform to the same.

\section{Conclusion}

We contend that the author private sector's involvement in higher education provision needs to be more robust than it is today. The present competitive world is not so easy for Zambian private and public higher education institutions to offer science and technology-biased subject areas for the steaming population. But we strongly argue that it is better if adequate measures are taken. With the private and public higher education institutions working together, seemingly neglected science and technology subject areas can be enhanced. Institutions of higher education in Zambia have burdens of cross-currents of the country, the market and civil society. 
This leaves them with a 'demand overload' situation; necessitating them to cope with an enormous range of aims, goals, obligations, anticipations and demands, economic pressures, public expectations and institutional stakeholder demands. Alluding to this Saleem Badat (2009:12) says: They must often do so with difficulty in securing and retaining specialist person-power, which is increasingly attracted to the better remuneration offered by the public and private sectors; without adequate public finances; with limited scope for increased finance from uition income, and with various difficulties posed by income from other sources. Simultaneously, they must remain faithful to the 'public good' ideals of higher education.

\section{References}

Boyer, E. (1990) Scholarship Reconsidered: Priorities for the Professoriate. Princeton: Carnegie Foundation for the Advancement of Teaching, University of Princeton.

Carnoy, M. (1998) 'Higher Education in a Global Innovation Economy'. Paper presented at a Joint Centre for Higher Education Transformation and Human Sciences Research Council Seminar on Globalisation, Higher Education, High-Level Training, and National Development, Pretoria, 31 July

Castells, M. (1993) 'The University System: Engine of Development in the New World Economy', in Ransom, A. et al (ed.) Improving Higher Education in Developing Countries. Washington D.C.: World Bank

Castells, M. (2001) 'Universities as Dynamic Systems of Contradictory Functions', in Müller, J., Cloete, N, \& Badat, S. (eds.) Challenges of Globalisation: South African Debates with Manuel Castells. Cape Town: Maskew Miller Longman

Delanty, G. (2001). Challenging Knowledge: The University in the Knowledge Society. Buckingham: The Society for Research into Higher Education \& Open University Press

Gould, S.J. (2006).http://prelectur.stanford.edu/lecturers/gould/excerpts/index. html\#popsci; Accessed 15 September 2006; 18.05

Maliyamkono, T. L. and Mason, H. (2006). The Promise. Dar-es-Salaam: TEMA Publishers Company Ltd.

Melucci, A. (1989).Nomads of the Present: Social Movements and Individual Needs in Contemporary Society. Philadelphia: Temple University Press

Merisotis, J.P. and Phipps, R.A. (1999). What is the difference.

Makwandire, T (2009) 'Preface' in The British Academy and the Association of Commonwealth Universities (2009) The Nairobi Report: Frameworks for Africa-UK Research Collaboration in the Social Sciences and Humanities. London: The British Academy and the Association of Commonwealth Universities

MoE (1996). Educating Our Future, National Policy on Education. Lusaka: Ministry of Education.

Mulenga, A. (February, 2010). Tertiary education in Zambia is a disaster, observes ZANEC. The Post Newspaper, Lusaka.

Northern Rhodesia (1963). African Education, Annual Summary for the year 1961. Lusaka: Government Printers. O’Neill,K. Singh, G. and O’Donoghue, J. (2004). Implementing e-learning programmes.

Stanton, T.K. (2008). 'Introduction' in Service-Learning in the Disciplines: Lessons from the Field. Pretoria: Council on Higher Education/JET Education Services. 